\title{
Categorization of Project Complexity Factors In Malaysian Construction Industry
}

\author{
Abdou Saed M', Kuan Yong ${ }^{2}$, Mohamed Othman ${ }^{3}$ \\ Faculty of Built Environment, University of Malaya, Malaysia \\ *Corresponding author: saed@siswa.um.edu.my
}

\begin{abstract}
The disagreement on project complexity is a crucial problem as project complexity is closely related to the project management process particularly for the construction industry. Due to its negative influence on project management process, project complexity therefore needs to be understood and managed efficiently particularly in construction projects. The literature review uncovered the disagreement on project complexity varied interpretation in which analysis of its essential concepts was provided. The intention of this paper is to provide an understanding on the project complexity and its implications on the construction projects and to stimulate debate on this controversial topic. This paper intends to determine and categorise factors for project complexity influencing the construction projects in Malaysia. The data were collected through a survey of 101 respondents. The results indicated that, there are three categories of project complexity factors that influence the construction project in Malaysia. It is concluded that the project complexity concept is worthy to be studied further.
\end{abstract}

Key Words: Complexity Factors; Construction Projects; Project Complexity; Project Management

\section{INTRODUCTION}

The construction industry is widely influenced by project complexity. However, the nature of project complexity is a subject matter that has yet to be explored. The studies that investigate complexity factors and its drivers are limited. In addition, the term "Complexity" is not well defined in the literature. Although previous authors have proposed for more investigation on managing complex project, project performance and process have been said to be interrelated to project complexity. Therefore, project complexity should have a clear definition that can precisely be measured in order to achieve operational project complexity management. Nevertheless, it is important to mention that the complexity can have negative effect on projects and its outcomes as the influences developed from complexity can lead to specific new perspectives. Constructions projects, especially mega projects, involving large number of parties and their interconnections tend to generate complexity with defined characteristics. The complexity of projects in Malaysia's construction sector pose a great challenge in managing these projects. Hence, it is important to understand the complexity of the project context during the project process rather than decreasing or avoiding it totally. It is important for construction project managers to manage tasks as they are characterised by various interdependent components. They also need to be aware of cases with problem of integration within their projects (Baccarini, 1996). By defining the project complexity measures, the aspects of defining

\footnotetext{
1 Postgraduate student, Faculty of Built Environment, University of Malaya, Kuala Lumpur, Malaysia; Email: saed@siswa.um.edu.my

2 Senior lecturer, Department of Architecture, University of Malaya, Kuala Lumpur, Malaysia; Email: kuanyong@um.edu.my 3 Senior lecturer, Department of Quantity Survey, University of Malaya, Kuala Lumpur, Malaysia; Email: othmanmohamed@um.edu.my
} 
the project objects, attributes and linking them more efficiently with the project performance could be enhanced so as to reduce the negative influence on project performance.

\section{LITERATURE REVIEW}

The construction projects particularly mega projects display complexity through many varied features (Chan et. al., 2004i ; Lucas, 2005). The understanding and management of project complexity is of essential importance because of the increasing complexity in managing major construction projects that have posed great challenges for the construction industry (Baccarini, 1996) (Williams, 2002). Moreover, it is agreed that the complexity understanding is vital for project management because of the difficulties and challenges associated with decision-making and goal accomplishment. Therefore, it can be eventually be influenced by the relation between the project performance and project complexity (Chan et. al., 2004a). While the significance of project complexity in project management field has been extensively recognised (Parsons-Hann, 2005; Vidal \& Marle, 2008), there is a lack of independent examination that exist for project complexity evaluation, due to its complexity that is mainly linked to preconception of stakeholders (Corning, 1998; Pich, 2002).

As the construction industry is continuously growing and becomes very complicated, it is vital to recognise the concept of project complexity in the industry that has been challenged with unlimited difficulties of managing mega construction projects (Bosch-Rekveldt, 2011; Williams, 2002). Despite of the extensive exploration of the complexity concept, there is no agreement on the attributes of project complexity. It has been emphasised by Sinha et.al. (2006)(Sinha et.2006) that complexity concept cannot be sufficiently gathered by one single definition. The word "complexity" can be observed by several perspectives in different fields as well as in the same field. Therefore, project complexity needs to be understood and the complexity measures need to be efficiently identified for better contribution to modern project management knowledge (Bryde, 2008; Vidal \& Marle, 2008).

\section{PROJECT COMPLEXITY DEFINITION}

Project complexity appears to be a broad, ambiguous concept and the complexity term is used mainly in the construction industry. The variety of perceptions and frameworks concerning this concept support the difficulty of reaching a coherent and broadly supported definition of project complexity. It has been highlighted earlier that that there is no consensus on the definition of project complexity because the bases of complexity are definite, various, dynamic, and uncertain which makes it difficult to define complexity (Calinescu et. al., 1998; Chu et. al., 2003; Jaafari, 2003). By defining the complexity key drivers, the difficulty in defining complexity can be minimised, although there is difficulty in defining those key drivers in the field of project management as well as in other fields (Koivu et. al., 2004; Sinha et. al., 2011). Through identifying the ' project context' that takes into account of time, work and social environment of the project, it would be essential for forming project complexity (Sinha et al., 2011). For example, project complexity can be reviewed from the perspectives of the differences and the interdependency of project organisations by determining two types of complexities: organisational and technological complexity (Baccarini, 1996). (Williams, 2002) Williams (2002) has used Baccarini's definition and named it structural complexity and extended the definition by adding social psychological elements of complexity: uncertainty complexity. The latter would comprise the extent to which the goals are well defined and the extent 
of well-defined methods in order to achieve these goals. Moreover, it has been indicated that welldefined project complexity include the changed features such as "the property of a model which makes it difficult to formulate its overall behavior in a given language, even when given reasonably complete information about its atomic components and their inter-relations"(Edmonds, 1999 p47). Another classification that was proposed by (Lucas, 2005) is that complexity comprise a complex system that consists of several elements interacting with each other in many different ways.

\section{COMPLEXITY TYPES}

An elaboration of the two (2) types of complexities that have been identified earlier are given as follows:

\subsection{Organizational}

It is a total of the categorised levels and/or, the amount of collaboration among the project administrative fundamentals, allocation of tasks, sharing of the responsibility for decision-making or the description for relationship in relations to communications (Laurikkala, 2001). Construction projects require organisation for a certain time period as they are typically categorised by a participation of many separate or varied administrations, for example the consultants and contractors (Edmonds, 1999)

\subsection{Technological}

It is the number of the inputs and outputs of the project and the interdependencies between tasks (Vidal \& Marle, 2008). It has been mentioned of the disagreement on the conceptual definition of technology that has been underlined widely in the literature. Due to technology, the term is commonly identified in relations to tasks; the term 'technology' and 'task' are constantly used. Technology is a transformation process which include exchange of inputs in outputs of a project (Baccarini, 1996). Therefore, technology can be categorised into three aspects: characteristics of knowledge, materials or equipment and arrangement of activities e.g. project tasks (Baccarini, 1996; Williams, 2002). Technological complexity can be present within the relationships between the project tasks that are interpreted into a varied clarification. This aspect of technological complexity contains extensive characteristics of the construction forms, location difficulties and operations design and planning (Corning, 1998).

\section{PROJECT COMPLEXITY INDICATORS}

It is suggested in the earlier review of the literature that the aspects essential for project complexity could be categorised in four classifications as shown in Figure 1. The categories are the key elements but they do not determine project complexity. They can be categorised as project size, project variety, project system interdependencies and/or interrelations. 


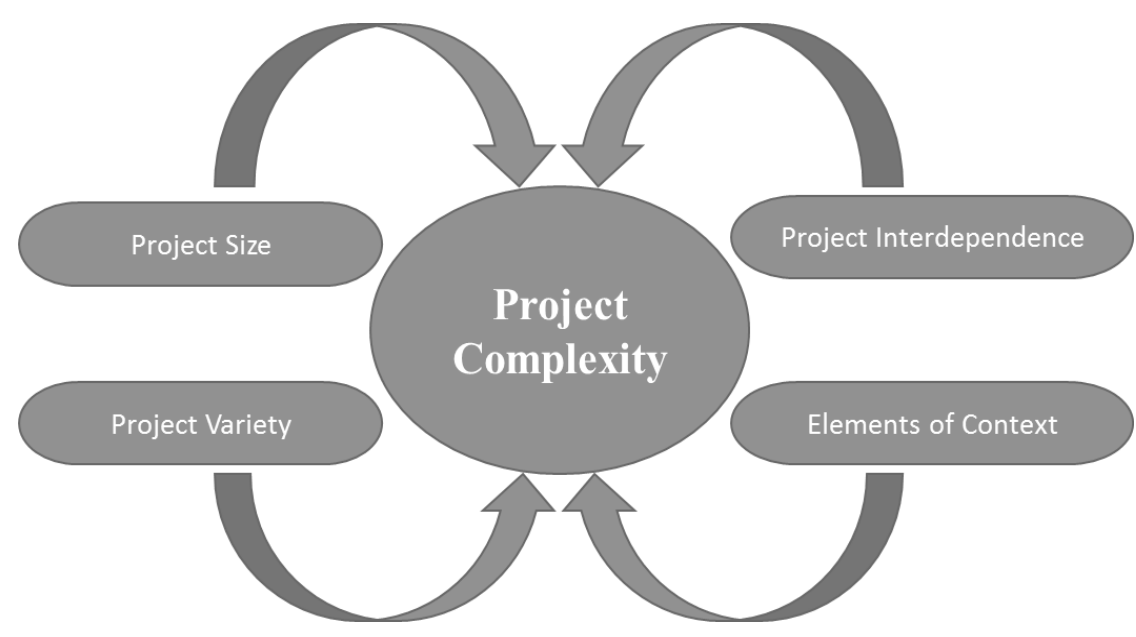

Figure 1. Project Complexity Indicators (Edmonds, 1999)

A brief explanation of these indicators (Edmonds, 1999) is discussed in the following sub sections.

\subsection{Project Size}

The size of the project is a compulsory requirement for project complexity. It has been stated that in order to be considered as a complex structure organizational system must be over a critical size. That size defines the limitations and features of complexity in project system, and it is a core drivers of project complexity. (Corbett et. al., 2002; Cicmil \& Marshall, 2005)

\subsection{Project Variety}

It has been highlighted that project diversity is creating an influence with the developing possessions and hence on the project complexity (Jones \& Anderson, 2005). Diversity relates closely to the number of emergent properties as underlined by Corbett et.al. (2002).

\subsection{Project System Interdependencies}

This indicator is likely to be one of the key role elements on project complexity as highlighted by many authors. It has been reported the interrelationships between the project's components are more complex than is suggested by the traditional work breakdown structure of project network, suggesting that traditional project management implementation is not adequate to cater the certainty of interdependence (Koivu et. al., 2004).

\subsection{Context-dependence}

It has been reported that project context is a crucial driver of project complexity and can be a main driver of the complex system (Chu et al., 2003; Genelot, 2001). It was explained by Koivu et.al. (2004) (Koivu et al., 2004) that the context and practices that apply to one project are not directly transferable to other projects with different institutional and cultural configurations. Therefore, project complexity cannot neither be analysed nor managed without taking into account of the significances of the project context. 


\section{DATA COLLECTION}

After reviewing the project complexity definitions, indictors, types and factors, a total of 33 factors were evaluated in a questionnaire survey. It was conducted to define the factors that widely influence the project complexity. The questions were established for factors drawn from the literature review and also gathered from project managers, project management lecturers and project management professionals in Malaysian context. The respondents had appropriate experience with complex projects and are capable to deliver an actual input to the study area. The response from the project managers were constructive. However, as some of the responses were incomplete, a total of 101 responses (which represent $81.5 \%$ of the respondents) were used. The factors were assessed by using descriptive analysis (Likert scale) and the factors are then arranged in the various categories as shown in Table 1. For the purpose of this study, a complex project is defined by the number of tasks and their interdependencies, uncertainty, technical aspects etc., and the different models of complexity reviewed.

Table 1. Project Complexity Factors

\begin{tabular}{|l|l|l|}
\hline \multicolumn{1}{|c|}{ Technical Category } & \multicolumn{1}{|c|}{ Organizational Category } & \multicolumn{1}{|c|}{ Environmental Category } \\
\hline Number of project goals & Lack of resources \& skills & $\begin{array}{l}\text { Number of external } \\
\text { stakeholders }\end{array}$ \\
\hline Clarity of project goals & Lack of experience with partners & Political influence \\
\hline Uncertainties in scope & $\begin{array}{l}\text { Communication between different } \\
\text { parts of the organization } \\
\text { Availability of financial sources }\end{array}$ & $\begin{array}{l}\text { Required local contents } \\
\text { Interference between existing } \\
\text { sites }\end{array}$ \\
\hline $\begin{array}{l}\text { Strict quality } \\
\text { requirements }\end{array}$ & Number of contracts & Weather conditions \\
\hline Project duration & Number of different languages & Remoteness of location \\
\hline Number of locations & Involvement of different time-zones & $\begin{array}{l}\text { Lack of experience in the } \\
\text { country }\end{array}$ \\
\hline Advanced Technology & Size of project team & $\begin{array}{l}\text { Government environmental } \\
\text { regulations }\end{array}$ \\
\hline Number of tasks & Lack of trust in project team & $\begin{array}{l}\text { Instability of project } \\
\text { environment }\end{array}$ \\
\hline Variety of tasks & Lack company internal support & Level of competition \\
\hline Uncertainty in methods & Organizational risks & Environmental Risks \\
\hline Technical risks & &
\end{tabular}

\subsection{Target group profile}

The targeted respondents were categorized into three groups; project managers whose managing the project process and/or supervision process (71\%), project management professionals who have 10 or more years of experience (18\%) and project management lectures who teach project management at the Malaysian Universities (11\%). The main factors to differentiate between the respondents groups was years of experience, size of the project and level of complexity of the projects (see Figure 8). 


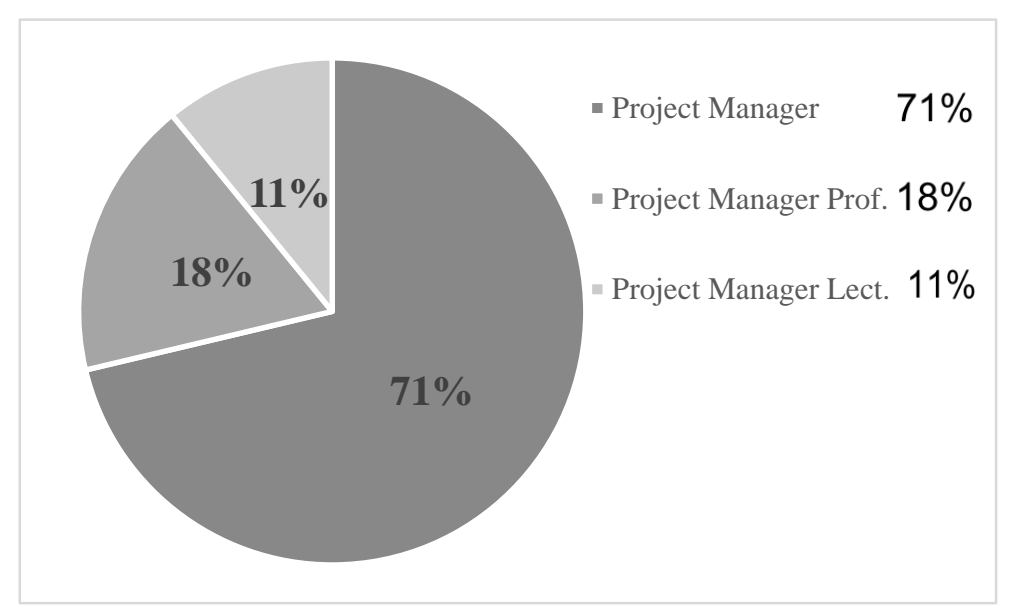

Figure 8. Target groups profile

\section{DATA ANALYSIS}

SPSS version 20.0 was used to analyse the data through the use of Principal Component Analysis (PCA).

\subsection{Sample Size}

The common strategies for the adequate sample size for factor analysis include the sample size of 100 or more. It has been reported that results with the correlation coefficients of $>0.80$ involve a smaller sample size (Guadagnoli, 1988). However, Sapnas (2002) has indicated that a sample size of 50 cases could be satisfactory for a factor analysis (Sapnas, 2002).

\subsection{Kaiser-Meyer-Olkin (KMO)}

The KMO value of 0.50 showed an appropriate result for factor analysis (the range, 0 to 1 ). This analysis means a significant $(\mathrm{p}<.05)$ Bartlett's test of sphericity (Tabachnick, 2007) as shown in Table 2.

Table 2. The KMO and Bartlett's Test

\begin{tabular}{|l|l|l|}
\hline \multicolumn{2}{|l|}{$\begin{array}{l}\text { Kaiser-Meyer-Olkin Measure of Sampling } \\
\text { Adequacy }\end{array}$} & 0.808 \\
\hline \multirow{3}{*}{$\begin{array}{l}\text { Bartlett's Test of } \\
\text { Sphericity }\end{array}$} & $\begin{array}{l}\text { Approx. Chi- } \\
\text { Square }\end{array}$ & $\begin{array}{l}1337.1 \\
40\end{array}$ \\
\cline { 2 - 3 } & df & 528 \\
\cline { 2 - 3 } & Sig. & 0.000 \\
\hline
\end{tabular}

\subsection{Extraction Method}

The Principal Component Analysis (PCA) is the common technique in various statistical analysis and the most commonly used is Confirmatory Factor Analysis (CFA) (Thompson, 2004). However, with no former concept or model exists, PCA is suggested to launch the initial results in Factor Analysis. For the purpose of this study, PCA was conducted. 


\subsection{Variance Percentage}

The Table 3 shows the growing variance of $40.294 \%$ with 3 factors showing eigenvalue $>1$. The outcomes as shown in Table 3 are adequate, as explained by variance as low as $50-60 \%$ (Pett et. al, 2003). These three factors were extracted using the PCA.

Table 3. Total Variance Explained

\begin{tabular}{|c|c|c|c|c|c|c|c|}
\hline \multirow[t]{2}{*}{$\begin{array}{l}\text { Compone } \\
\text { nt }\end{array}$} & \multicolumn{3}{|c|}{ Initial Eigenvalues } & \multicolumn{3}{|c|}{$\begin{array}{l}\text { Extraction Sums of Squared } \\
\text { Loadings } \\
\end{array}$} & \multirow{2}{*}{$\begin{array}{l}\text { Rotation Sums of } \\
\text { Squared Loadings } \\
\text { Total }\end{array}$} \\
\hline & Total & $\begin{array}{c}\% \text { of } \\
\text { Variance }\end{array}$ & $\begin{array}{c}\text { Cumulative } \\
\% \\
\end{array}$ & Total & \begin{tabular}{c|}
$\%$ of \\
Variance \\
\end{tabular} & $\begin{array}{c}\text { Cumulative } \\
\% \\
\end{array}$ & \\
\hline 1 & 9.316 & 28.232 & 28.232 & 9.316 & 28.232 & 28.232 & 6.536 \\
\hline 2 & 2.181 & 6.610 & 34.842 & 2.181 & 6.610 & 34.842 & 6.633 \\
\hline 3 & 1.799 & 5.452 & 40.294 & 1.799 & 5.452 & 40.294 & 6.374 \\
\hline
\end{tabular}

\subsection{Scree Plot}

The Scree test showed that three factors among the factors that has displayed a departure from linearity according to eigenvalues. Therefore, the Scree Plot showed that the statistics must be examined for these three factors.

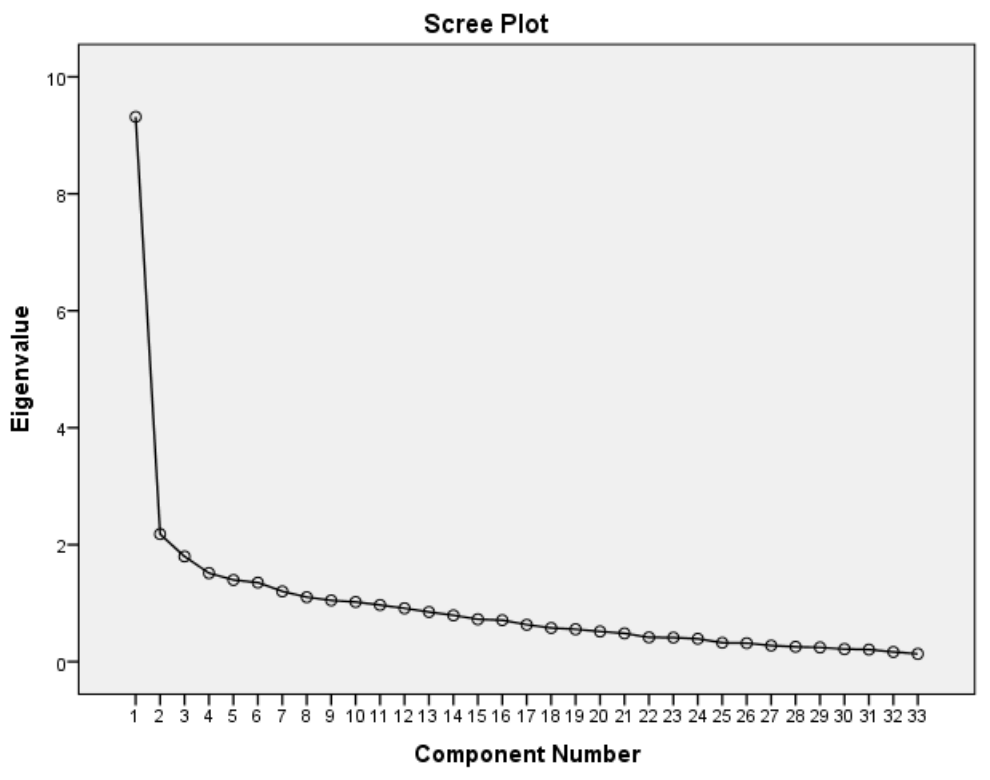

Figure 9. The Scree Plot

\subsection{Rotational Method}

Promax with Kaiser Normalization was the selected rotation method in which the rotation was converged in 18 iterations. 


\subsection{Interpretation}

The interpretation examine the variables attributed to a factor and how themes are then identified. These themes are then shown in a Pattern Matrix (Table 4).

\section{RESULTS AND FINDINGS}

The correlation between 33 components was examined using many valid procedures. It is perceived that several components are related by a minimum of 0.3 with one other item, signifying an accurate factorability. The KMO measure of sampling adequacy is 0.81 , that is beyond the suggested significance of 0.6, and Bartlett's test of sphericity is substantial $\left(\chi^{2}(528)=1337.14, \mathrm{p}<.05\right)$. The communalities are beyond 0.3 , which further confirms that certain items share some common variances.

The use of Principal Components Analysis (PCA) was to identify the scores for factors that highlight project complexity. The overall variance explained through the use of Promax rotation method with Kaiser Nomalisation rotations was $40.294 \%$ based on the original eigenvalues. From that result, eight items were disqualified because they failed to meet the minimum standards of main factor loading of $\geq 0.4$ and did not contribute to a simple factor structure as shown in Table 4 .

Table 4. The Pattern Matrix

\begin{tabular}{|c|c|c|c|c|}
\hline \multirow[t]{2}{*}{ No. } & \multirow[t]{2}{*}{ Factor } & \multicolumn{3}{|c|}{ Component } \\
\hline & & 1 & 2 & 3 \\
\hline 1 & Number of project goals & .540 & & \\
\hline 2 & Clarity of project goals & .432 & & \\
\hline 3 & Uncertainties in scope & .491 & & \\
\hline 4 & Strict quality requirements & & & .489 \\
\hline 5 & Project duration & & .502 & \\
\hline 6 & Number of locations & & .741 & \\
\hline 7 & Advanced Technology & & & .473 \\
\hline 8 & Number of tasks & & & .706 \\
\hline 9 & Variety of tasks & & & .596 \\
\hline 10 & Uncertainty in methods & .488 & & \\
\hline 11 & Technical risks & .423 & & \\
\hline 12 & Lack of resources \& skills & & & .518 \\
\hline 13 & Lack of experience with partners & & & .726 \\
\hline 14 & Availability of financial sources & & & .601 \\
\hline 15 & Number of contracts & & & .461 \\
\hline 16 & Number of different languages & & .534 & \\
\hline 17 & Involvement of different time-zones & .452 & & \\
\hline 18 & Size of project team & .695 & & \\
\hline 19 & Lack of trust in project team & .486 & & \\
\hline 20 & Organizational risks & .480 & & \\
\hline 21 & Number of external stakeholders & & .426 & \\
\hline 22 & Required local contents & & & .557 \\
\hline 23 & Interference between existing sites & & .551 & \\
\hline 24 & Weather conditions & & .797 & \\
\hline 25 & Remoteness of location & & .575 & \\
\hline 26 & Government environmental regulations & .444 & & \\
\hline 27 & Level of competition & .471 & & \\
\hline 28 & Environmental Risks & & .448 & \\
\hline
\end{tabular}




\section{DISCUSSION}

Having analysed the data using PCA, the data was adequate and valid to implement Principal Components Analysis (PCA); with KMO results for each factor ( $>0.90)$ were above 0.5 and the Kaiser-Meyer-Olkin Measure (KMO) was 0.8.

The three factor categories can be an approach to assess the measuring of project complexity in Malaysian construction industry by identifying the element causing project complexity for better managing and controlling on projects. In addition, significant correlations were found between separate complexity components and perceptions of complexity, although it was also suggested that the respondents commonly focus more on the inferences or concerns of project complexity rather than its causes. Table 5 shows the twenty eight (28) factors.

Table 5. Factor Loading after Rotation

\begin{tabular}{|c|c|c|c|c|}
\hline & Factors & Technical & Environmental & Organizational \\
\hline 1 & Number of project goals & & & .540 \\
\hline 2 & Clarity of project goals & & & .432 \\
\hline 3 & Uncertainties in scope & & & .491 \\
\hline 4 & Strict quality requirements & .489 & & \\
\hline 5 & Project duration & & .502 & \\
\hline 6 & Number of locations & & .741 & \\
\hline 7 & Advanced Technology & .473 & & \\
\hline 8 & Number of tasks & .706 & & \\
\hline 9 & Variety of tasks & .596 & & \\
\hline 10 & Uncertainty in methods & & & .488 \\
\hline 11 & Technical risks & & & .423 \\
\hline 12 & Lack of resources \& skills & .518 & & \\
\hline 13 & Lack of experience with partners & .726 & & \\
\hline 14 & Availability of financial sources & & & \\
\hline 15 & Number of contracts & .601 & & \\
\hline 16 & Number of different languages & .461 & & \\
\hline 17 & Involvement of different time-zones & & .534 & \\
\hline 18 & Size of project team & & & .452 \\
\hline 19 & Lack of trust in project team & & & .695 \\
\hline 20 & Organizational risks & & & .486 \\
\hline 21 & Number of external stakeholders & & & \\
\hline 22 & Required local contents & & & .480 \\
\hline 23 & Interference between existing sites & & .426 & \\
\hline 24 & Weather conditions & & & \\
\hline 25 & Remoteness of location & .557 & & \\
\hline 26 & Government environmental regulations & .444 & & \\
\hline 27 & Level of competition & .471 & & \\
\hline \multirow[t]{3}{*}{28} & Environmental Risks & & .448 & \\
\hline & Eigenvalues & 9.3 & 2.2 & 1.8 \\
\hline & $\%$ of Variance & $28.2 \%$ & $6.6 \%$ & $5.5 \%$ \\
\hline
\end{tabular}

Through the evaluation of gathered data from the survey, the factors of project complexity that influence construction projects in Malaysia have been identified. It is concluded that project complexity negatively influences project process. Table 6 shows the three factor groups of project complexity factors that have been identified. 
Table 6. Three-factor groups of project complexity

\begin{tabular}{|l|l|l|}
\hline Technical & Environmental & Organizational \\
\hline Strict quality requirements & Project duration & Number of project goals \\
\hline Advanced Technology & Number of locations & Clarity of project goals \\
\hline Number of tasks & Involvement of different time-zones & Uncertainties in scope \\
\hline Variety of tasks & Interference between existing sites & Uncertainty in methods \\
\hline Lack of resources \& skills & Environmental Risks & Technical risks \\
\hline Lack of experience with partners & & Size of project team \\
\hline Number of contracts & & Lack of trust in project team \\
\hline Number of different languages & & Organizational risks \\
\hline Remoteness of location & & Required local contents \\
\hline $\begin{array}{l}\text { Government environmental } \\
\text { regulations }\end{array}$ & & \\
\hline Level of competition & & \\
\hline
\end{tabular}

From the above table, a three-factor group of project complexity is displayed comprising the following complexity factor groups: (i) Number of tasks, Lack of resources \& skills, Number of contracts etc. are complex elements are categorized under the "Technical Complexity Factor". (ii) Project duration, Number of locations, Number of different languages etc. are complex elements under the "Environmental Complexity Factor" and (iii) Number of project goals, Size of project team, Uncertainty in methods etc. are the complex variable elements under "Organizational Complexity Factor".

\section{CONCLUSION}

A few concerns have been raised within the project management field on the project complexity factors. Among them include; the lack of project complexity models due to the deficiency of the understanding of these measures effect on the projects; the lack of effective action to be implemented considering the existing and new complexity measures; successful project management depends on the proper decision taken according to the project characteristics and project complexity must be understood in relations to interdependencies and diversity of tasks in projects.

This paper provides an insight to the aspect project complexity and raises the motivation to investigate the subject further. As projects gradually become more complex, there is an increasing demand to understand project complexity concept and its impact on the project process and performance. In order to reach enhanced levels of project performance, project complexity has to be managed professionally. Project managers should be more involved in acknowledging active complexity models and measures in order to understand the complexity level and the factors within the construction projects. Moreover, by understanding this concept, it is hoped that the project managers are able to evaluate project complexity so that the project performance can be enhanced further for the betterment of the project performance in Malaysia. 


\section{REFERANCES}

Baccarini, D. (1996). The concept of project complexity—a review. International Journal of Project Management, 14(4), 201-204.

Bosch-Rekveldt, M. (2011). Managing project complexity. Delft Centre for Project Management, the Netherlands., ISBN 978-94-91005-00-8.

Bryde, D. (2008). Perceptions of the impact of project sponsorship practices on project success. International Journal of Project Management, 26(8), 800-809.

Calinescu, A., Efstathiou, J., Schirn, J., \& Bermejo, J. (1998). Applying and assessing two methods for measuring complexity in manufacturing. Journal of the Operational Research Society, 723-733.

Chan, A. P., Scott, D., \& Chan, A. P. (2004a). Factors affecting the success of a construction project. Journal of construction engineering and management.

Chan, A. P., Scott, D., \& Chan, A. P. (2004b). Factors affecting the success of a construction project. Journal of construction engineering and management, 130(1), 153-155.

Chu, D., Strand, R., \& Fjelland, R. (2003). Theories of complexity. Complexity, 8(3), 19-30.

Cicmil, S., \& Marshall, D. (2005). Insights into collaboration at the project level: complexity, social interaction and procurement mechanisms. Building Research \& Information, 33(6), 523-535.

Corbett, L., Brockelsby, J., \& Campbell-Hunt, C. (2002). Tackling industrial complexity. Tackling Industrial Complexity, 83-96.

Corning, P. A. (1998). Complexity is just a word! Technological Forecasting and Social Change, 59(2), 197-200.

Edmonds, B. (1999). Syntactic measures of complexity. University of Manchester.

Genelot, D. (2001). Manager dans la complexité: réflexions à l'usage des dirigeants: INSEP éditions.

Guadagnoli E, V. W. (1988). Relation of sample size to the stability of component patterns. Psychological Bulletin, 103(2):265-75.

Jaafari, A. (2003). Project management in the age of complexity and change. Project Management Journal, Vol. 34 No. 4, pp. 47-57.

Jones, B. S., \& Anderson, P. (2005). Diversity as a determinant of system complexity. Complexity in Design and Engineering.

Koivu, T., Nummelin, J., Tukiainen, S., Tainio, R., \& Atkin, B. (2004). Institutional complexity affecting the outcomes of global projects.

Koivu, T., Nummelin, J., Tukiainen, S., Tainio, R. and Atkin, B. . (2004). Institutional complexity affecting the outcomes of global projects. VTT Working Papers 14, VTT, Espoo.

Laurikkala, H., Puustiner, E., Pajarre, E. and Tanskanen, K. . (2001). Reducing complexity of modelling in large delivery projects. Proceedings of the International Conference on Engineering Design, ICED'01, Glasgow, Vol. 1, Professional Engineering Publishing, Bury St Edmunds, pp. 165-72.

Lucas, C. (2005). The philosophy of complexity. On-line at www. calresco. org, retrieved August, 8, 2011.

Parsons-Hann, H. a. L., K. . (2005). Measuring requirement complexity to increase the probability of project success. Proceedings of ICEIS 2005, Miami, Florida, USA, pp. 434-8.

Pett MA, L. N., Sullivan JJ. . (2003). Making Sense of Factor Analysis: The use of factor analysis for instrument development in health care research. Sage Publications Inc.

Pich, M. T., Loch, C.H. and de Meyer, A. (2002). On uncertainty, ambiguity, and complexity in project management. Management Science, Vol. 48 No. 8(pp. 1008-23).

Sapnas KG, Z. R. (2002). Minimizing sample size when using exploratory factor analysis for measurement. Journal of Nursing Measurement, 10(2):135-53.

Sinha, S., Kumar, B., \& Thomson, A. (2011). Complexity measurement of a project activity. International Journal of Industrial and Systems Engineering, 8(4), 432-448. 
Sinha, S., Kumar, B., \& Thomson, A. . (2006). Measuring project complexity: a project manager's tool. Architectural Engineering and Design Management, 2(3), 187-202.

Tabachnick BG, F. L. (2007). Using Multivariate Statistics. Boston: Pearson Education Inc.

Thompson. (2004). Exploratory and confirmatory factor analysis: understanding concepts and applications. American Psychological Association.

Vidal, L.-A., \& Marle, F. (2008). Understanding project complexity: implications on project management. Kybernetes, 37(8), 1094-1110.

Williams, T. (2002). Modelling complex projects. 


\title{
Appendix “A” QUESTIONNAIRE SURVEY
}

\author{
QUESTIONNAIRE SURVEY
}

"The Influence of Project Complexity on Project Management Performance"

\begin{abstract}
Aim of the questionnaire:
This questionnaire investigates "The Influence of Project Complexity on Project Management Performance". You are invited to participate in a research study, undertaken as a part of a Master degree fulfillment at the Faculty of Built Environment, University of Malaya. The research aims to examine the Influence of project complexity on project Management performance and assess how it can contribute to project outcomes. Your answer will be extremely helpful in conducting this research project. All details and answers given will be kept confidential.
\end{abstract}

\section{Project Complexity Definition:}

It is proposed that project complexity can be defined as "consisting of many varied interrelated parts and can be operationalized in terms of differentiation and interdependency". This definition can be applied to any project dimension relevant to the project management process, such as organization, technology, environment, information decision making and systems. (Baccarini, 1998)

\section{Respondents particular:}

Please tick ( $\searrow$ an appropriate answer in the following box:

1. The role of your profession:
A project manager
A project management professional
A project management lecturer
Other:

2. Years of experience in Project Management:
OLess than 5 years
Between 5 to 10 years
More than 10 years

3. Size of the project team you work with:
O Small (10-50)
Medium-sized (50-250)
O Large (more than 250)

4. Range of complexity in project (s) you manage:

Osimple ONon-Complex OComplicated

5. Level of understanding of Project Complexity:
$\bigcirc$ Low
O Average
O High

\section{Project complexity factors}

Listed below are three categories of project complexity factors that influence the project performance, kindly rank each of the following: 
(1.strongly disagree, 2.disagree, 3.Neither, 4.agree, 5.strongly agree)

\begin{tabular}{|c|c|c|c|c|c|c|}
\hline No. & Project Complexity Factors & 1 & 2 & 3 & 4 & 5 \\
\hline \multicolumn{7}{|c|}{ 1.Technical Category: } \\
\hline 1 & Number of project goals & & & & & \\
\hline 2 & Clarity of project goals & & & & & \\
\hline 3 & Uncertainties in scope & & & & & \\
\hline 4 & Strict quality requirements & & & & & \\
\hline 5 & Project duration & & & & & \\
\hline 6 & Number of locations & & & & & \\
\hline 7 & Advanced Technology & & & & & \\
\hline 8 & Number of tasks & & & & & \\
\hline 9 & Variety of tasks & & & & & \\
\hline 10 & Uncertainty in methods & & & & & \\
\hline \multirow[t]{2}{*}{11} & Technical risks & & & & & \\
\hline & Others: & & & & & \\
\hline \multicolumn{7}{|c|}{ 2.Organizational Category: } \\
\hline 1 & Lack of resources \& skills & & & & & \\
\hline 2 & Lack of experience with partners & & & & & \\
\hline 3 & Communication between different parts of the organization & & & & & \\
\hline 4 & Availability of financial sources & & & & & \\
\hline 5 & Number of contracts & & & & & \\
\hline 6 & Number of different languages & & & & & \\
\hline 7 & Involvement of different time-zones & & & & & \\
\hline 8 & Size of project team & & & & & \\
\hline 9 & Lack of trust in project team & & & & & \\
\hline 10 & Lack company internal support & & & & & \\
\hline \multirow[t]{2}{*}{11} & Organizational risks & & & & & \\
\hline & Others: & & & & & \\
\hline \multicolumn{7}{|c|}{ 3.Environmental Category: } \\
\hline 1 & Number of external stakeholders & & & & & \\
\hline 2 & Political influence & & & & & \\
\hline 3 & Required local contents & & & & & \\
\hline 4 & Interference between existing sites & & & & & \\
\hline 5 & Weather conditions & & & & & \\
\hline 6 & Remoteness of location & & & & & \\
\hline 7 & Lack of experience in the country & & & & & \\
\hline 8 & Government environmental regulations & & & & & \\
\hline 9 & Instability of project environment & & & & & \\
\hline 10 & Level of competition & & & & & \\
\hline \multirow[t]{2}{*}{11} & Environmental Risks & & & & & \\
\hline & Others: & & & & & \\
\hline
\end{tabular}

\section{Frameworks / models for measuring project complexity}

Listed below are frameworks/models for measuring project complexity, kindly rank each of the following models: 
(1.strongly disagree, 2.disagree, 3.Neither, 4.agree, 5.strongly agree)

\begin{tabular}{|c|c|c|c|c|c|c|}
\hline No. & Frameworks or models for measuring project complexity & 1 & 2 & 3 & 4 & 5 \\
\hline 1 & Goals and Methods Matrix by Turner \& Cochrane & & & & & \\
\hline 2 & Stacey’s Agreement \& Certainty Matrix & & & & & \\
\hline 3 & Complexity Model suggested by Terry Williams & & & & & \\
\hline 4 & Adam Kahane's approach to complexity & & & & & \\
\hline 5 & Cynefin Decision Making Framework & & & & & \\
\hline 6 & Remington \& Pollack Model & & & & & \\
\hline
\end{tabular}

6. Name which of the project complexity models used in Malaysia:

\section{Thank you for your effort and kind cooperation}

